\title{
Desain Halte Bis Surabaya Dengan Tema Ikonik
}

\author{
Yohanes Firananta Setyo Atmono ${ }^{1 *}$ \\ ${ }^{I}$ Jurusan Desain Produk, Institut Sains dan Teknologi Terpadu Surabaya, Surabaya, Indonesia
}

\begin{tabular}{l|l|l} 
Received: August 2021 & Acepted: September 2021 & Published: October 2021
\end{tabular}

\begin{abstract}
Bus shelter for public transport in Surabaya has been made to accommodate the needs of the Department of Transportation and government city. This facilities built to attract public interest to using public transportation. Currently, several shelter Surabaya Bus have been built, but the existing conditions of the bus stops have not met the requirements. Therefore it is necessary to design a Surabaya bus stop that offers convenience, security and most importantly introduces the city of Surabaya both for tourist purposes and for city branding. There is a need for shelters that are designed aesthetically, comfortably and the most important thing is that users feel safe when they are at bus stops. Designed by paying attention to the overall design principles, namely the character of the user, both disabled and normal, user activities and support facilities. Exterior and interior bus shelter concept design use tropical and iconic ornaments from Surabaya iconic places.
\end{abstract}

Key words: Bus shelter design, aesthetic,Surabaya iconic theme,

\begin{abstract}
Abstrak
Halte bis untuk angkutan umum di Surabaya telah dibuat untuk mengakomodir kebutuhan Dinas Perhubungan dan pemerintah kota. Fasilitas ini dibangun untuk menarik minat masyarakat menggunakan transportasi umum. Saat ini telah diabngun beberapa halte Bis Surabaya, namun kondisi eksisting halte belum memenuhi syarat. Oleh karenanya perlu di di rancang halte bis Surabaya yang menawarkan kemudahan, keamanan dan yang terpenting adalah memperkenalkan kota Surabaya baik untuk tujuan wisata maupun city branding. Adanya kebutuhan halte yang di desain secara estetis, nyaman dan paling penting adalah pengguna merasa aman saat berada di halte. Didesain dengan memperhatikan prinsip desain secara keseluruhan yaitu karakter pengguna, baik penyandang cacat maupun normal, aktivitas pengguna dan fasilitas pendukung. Konsep desain eksterior dan interior halte bus menggunakan ornament tropis dan ikonik dari tempat-tempat ikonik Surabaya.
\end{abstract}

Kata kunci: Desain halte bis, estetika, tema ikonik Surabaya

\section{Pendahuluan}

Saat ini, bidang transportasi di Indonesia sedang digencarkan dengan munculnya transportasi berbasis aplikasi atau biasa disebut dengan transportasi online. Sebagai kota terbesar kedua di Indonesia, kota Surabaya pun turut serta dalam bisnis transportasi online. Kehadiran dari transportasi online memiliki beberapa dampak bagi kota Surabaya. Adapun dampak positif adalah kemudahan dalam melakukan perpindahan tempat. Sedangkan dampak negatif adalah jalan di kota Surabaya semakin macet dan polusi meningkat.

Bagi pemerintah kota Surabaya, kehadiran transportasi online ini dapat dimanfaatkan sebagai support system transportation yaitu sebagai moda penghubung pada jalur yang belum dilayani oleh moda transportasi public [1]. Saat ini pemerintah kota Surabaya telah membuat moda transportasi publik yang mudah diakses dan digunakan yaitu Bis Suroboyo atau Bis Surabaya. Sarana dan infrastruktur telah dibangun di beberapa titik dengan pembangunan halte Bis Suroboyo. Namun demikian, pembangunan halte ini belum dirancang secara maksimal mengingat fungsi penting halte lainnya adalah sebagai sarana city branding maupun untuk mendukung

\footnotetext{
* Corresponding author : yohanes@stts.edu
} 
wisata kota selain sebagai fungsi utamanya yaitu tempat naik maupun turunnya penumpang bis. Saat ini pemerintah kota Surabaya sedang menggiatkan wisata dan city branding kota Surabaya dengan cara menambah taman kota, fasilitas publik yang ramah anak, pusat kuliner dan tempat rekreasi keluarga.

Namun dalam kenyataannya, ada kekurangan dari halte di Surabaya yaitu banyak dari halte ini berada di area outdoor yang tidak memiliki pelindung dari cuaca panas terik maupun dalam cuaca hujan, selain itu fasiltas duduk atau tunggu tidak memadai bagi calon penumpang dari sisi kenyamanan. Hal lainnya adalah tidak adanya pengadaan papan informasi yang berisi info tentang angkutan umum Bis Suroboyo, tidak adanya fasilitas keamanan seperti CCTV, sering ditemukan bahwa halte digunakan untuk iklan - iklan liar, kerusakan pada halte akibat ulah masyarakat yang tidak tertib, ruang halte yang tidak bisa menampung banyak orang, dan lain - lain sehingga masyarakat kota Surabaya kurang tertarik untuk menggunakan Bis Suroboyo.

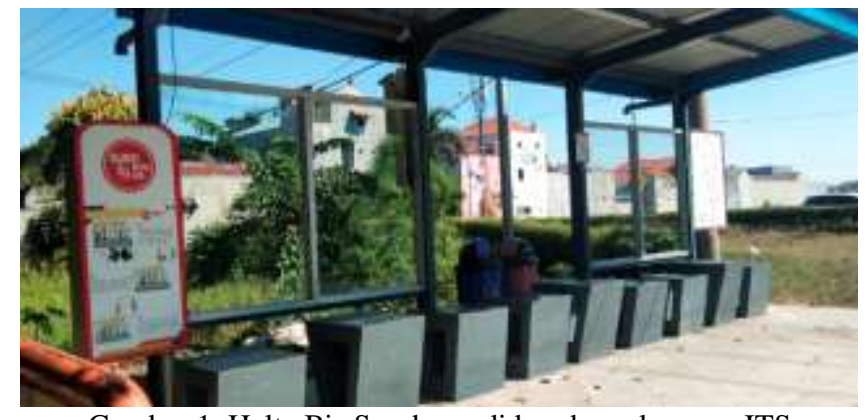

Gambar 1. Halte Bis Suroboyo di bundaran kampus ITS

Melihat masalah yang ada diatas, maka perlu adanya perancangan halte yang lebih baik sehingga tujuan utama dapat terpenuhi yaitu masyarakat semakin banyak yang menggunakan Bis Suroboyo dan fungsi halte sebagai sarana pendukung wisata dan city branding dapat dilakukan sehingga rencana strategis pemerintah kota Surabaya dapat terlaksana.

\section{Metodologi}

Dalam perancangan ini, penulis telah menyusun metodologi desain dengan uraian tahapan proses perancangan dengan metodologi sebagai berikut :

\section{Ide /Gagasan}

Ide atau gagasan adalah membahasan tentang hal-hal yang melatarbelakangi penelitian untuk memilih judul. Dalam latar belakang ini, dilakukan pengamatan untuk mengamati situasi lingkungan sekitar yang menjadi target objek penelitian untuk mengetahui masalah apa saja yang terjadi di lingkungan sekitar.

Perumusan Ide / Gagasan

Perumusan ide/gagasan merupakan aktivitas yang dilakukan untuk mendapatkan beberapa hal penting yang menjadi suatu permasalahan dalam satu kondisi. Masalah didefinisikan sebagai suatu pernyataan tentang keadaan yang belum sesuai dengan yang diharapkan. Masalah biasanya dianggap sebagai suatu keadaan yang harus diselesaikan. Dalam beberapa literatur riset, masalah seringkali didefinisikan sebagai sesuatu yang membutuhkan alternatif jawaban, artinya jawaban masalah atau pemecahan masalah bisa lebih dari satu. Gagasan awal pada desain perancangan ini adalah permasalahan sarana angkutan umum di kota Surabaya yaitu halte bis.

Pengumpulan Data

Pengumpulan data merupakan aktivitas yang dilakukan guna mendapatkan informasi yang diperlukan dalam rangka mencapai tujuan dari suatu penelitian. Beberapa cara pengumpulan data dalam penelitian ini adalah: Observasi, Interview / Wawancara, Kuisioner, Data Sekunder

\section{Konsep Desain}

Pada tahap ini dilakukan analisis dan identifikasi yang harus dipenuhi agar sesuai dengan kebutuhan dan aktivitas penumpang bis. Identifikasi dilakukan dengan hasil data yang telah diperoleh, hal ini bertujuan 
untuk mendapatkan poin kritikal yang diperlukan untuk menghasilkan desain yang dapat menyelesaikan permasalahan dalam perancangan ini.

Pendetailan Konsep

Pada tahap ini, konsep yang terpilih akan dikerjakan secara lebih detail. Proses perwujudan konsep dilakukan dengan langkah - langkah sebagai berikut: Penghitungan ukuran berdasarkan studi ergonomic, Pemodelan 3 dimensi, Gambar kerja, Model skala 1:10

\section{Lokasi Penelitian}

Lokasi penelitian dilakukan di 5 Halte Suroboyo Bus yang memiliki tingkat pengguna yang tinggi, memiliki sistem/fitur pelayanan yang menjadi acuan penulis dalam mendesain halte Suroboyo Bus yang baru serta merupakan halte yang menjadi fokus revitalisasi oleh Dinas Perhubungan Kota Surabaya Bersama dengan Pemerintah Kota Surabaya. Halte - halte yang dimaksud adalah sebagai berikut: Halte Bundaran ITS, Halte Basuki Rahmat, Halte Park \& Ride Mayjend Sungkono, Halte Joyoboyo, Halte Rajawali

\section{Analisa}

\subsection{Analisa Aktivitas}

Pada saat menunggu bis, responden melakukan suatu aktivitas baik aktivitas aktif maupun pasif. Pada observasi yang telah dilakukan, penulis mendapatkan 4 aktivitas utama yang dilakukan responden di dalam halte bus, yaitu : Makan / Minum, Menggunakan / bermain gadget, Membaca Koran / Majalah (bawa sendiri dari rumah), Tidak melakukan apa - apa

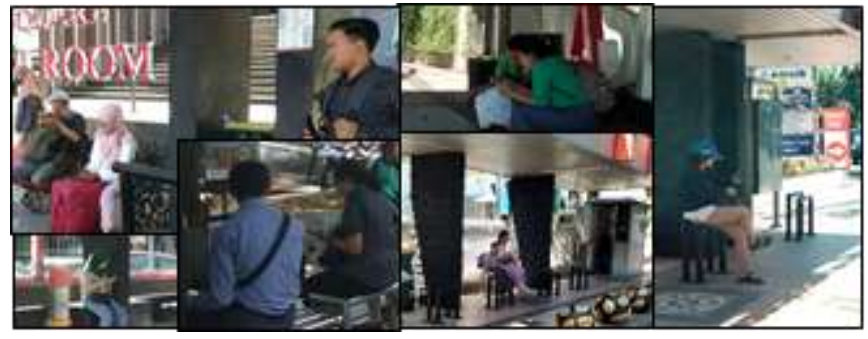

Gambar 2. Aktivitas Pengguna di Halte Basuki Rahmat

Namun di sisi lain, halte kurang menyediakan fasilitas pengisian daya (charger). Untuk itu, penambahan fasilitas seperti charging station dapat mengurangi permasalahan kehabisan daya dan menimbulkan rasa nyaman kepada responden. Untuk aktivitas membaca dan makan/minum didalam halte, fasilitas pendukung yang dapat membantu responden adalah tempat sampah untuk menampung sampah kertas/ plastik. Untuk tempat sampah, penempatan standar dari Pedoman Teknis Perekayasaan Tempat Perhentian Kendaraan Penumpang Umum [2] adalah diluar halte agar bau sampah tidak masuk langsung kedalam halte. Selain itu barang yang umum dibawa oleh responden saat menunggu kedatangan bus adalah botol / gelas plastik untuk menukarkan tiket/karcis Suroboyo Bus, Tas Ransel / Pinggang / Tas kecil.

Dari pengamatan tersebut, penulis akan mempertimbangkan untuk menambah space/ruang lebih bagi para pengguna yang membawa barang - barang tersebut. Salah satu cara adalah memberikan ruang pada fasilitas duduk yang lebih lebar agar masyarakat pengguna yang membawa barang, nantinya tidak kesulitan untuk meletakkan barang bawaan mereka.

\subsection{Analisa Kebutuhan}

\subsubsection{Fasilitas duduk}

Fasilitas duduk merupakan fasilitas yang penting dan dibutuhkan dalam halte. Fasilitas ini membantu responden merasa nyaman dalam menunggu bis dengan estimasi waktu 15 - 20 menit. Berdasarkan data syarat dan kebutuhan yaitu bentuk dari fasilitas duduk yang dipakai harus aman dan nyaman, namun tidak dapat untuk digunakan menjadi fungsi lain seperti untuk tidur. 
Berikut merupakan solusi atas ringkasan/rangkuman permasalahan yang ditemukan oleh penulis melalui observasi lapangan kepada responden, yaitu: 1) Menerapkan fasilitas duduk menggunakan material semen permanen seperti fasilitas duduk dengan pilihan responden terbanyak yaitu di Halte Basuki Rahmat, 2) Memperhatikan ujung dari fasilitas duduk agar tidak bersudut dan meminimalisir terjadinya cedera, 3) Ukuran tinggi dan alas dari fasilitas duduk halte harus sesuai kaidah ergonomic, 4) Memperbanyak, jumlah fasilitas duduk dan tunggu seperti menambahkan leaning rail bagi pengguna yang tidak mendapatkan tempat duduk.

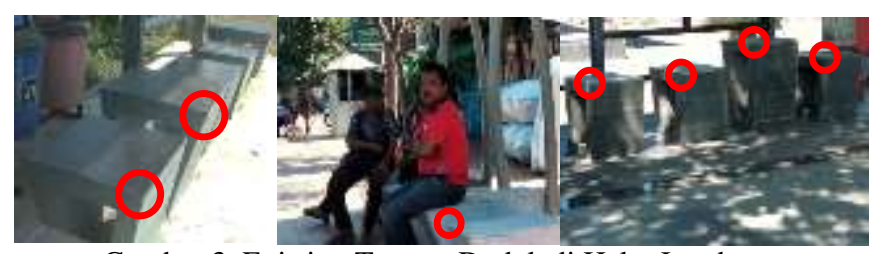

Gambar 3. Existing Tempat Duduk di Halte Joyoboyo

Tempat duduk bisa menjadi bagian tersendiri atau menyatu dengan halte. Pengadaan tempat duduk ini sangat direkomendasikan pada halte yang kerap dikunjungi oleh kaum difabel, ataupun mereka yang memiliki kesulitan berdiri dan berjalan kaki. Bentuk alternatif fasilitas duduk adalah sebagai berikut :

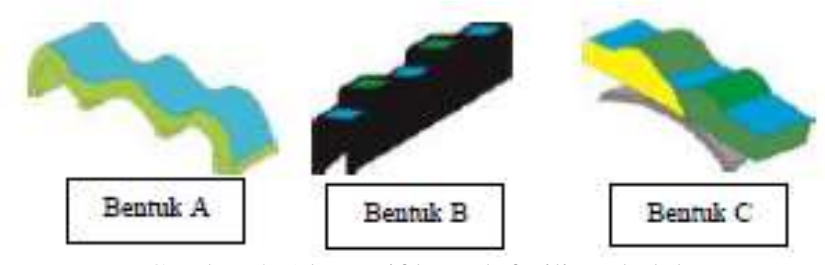

Gambar 4. Alternatif bentuk fasilitas duduk

Tabel 1. Perbandingan Bentuk Fasilitas Duduk

\begin{tabular}{lcccccc}
\hline & Kenyamanan & Estetika & Safety & Kemudahan produksi & Cost & Total \\
\hline Bentuk A & 5 & 7 & 4 & 4 & 7 & 27 \\
\hline Bentuk B & 7 & 6 & 8 & 8 & 6 & 35 \\
\hline Bentuk C & 5 & 7 & 5 & 3 & 6 & 26 \\
\hline
\end{tabular}

Melihat tabel perbandingan, maka bentuk yang sesuai dan dapat digunakan dalam halte adalah bentuk B. Hal ini dikarenakan bentuk B memiiki safety dan kenyamanan yang ideal dibandingkan bentuk lainnya yang cenderung memiliki bentuk bergelombang sehingga meminimalkan ruang duduk bagi pengguna. Dari faktor estetika, bentuk B masih kurang daripada bentuk yang lain. Akan tetapi, faktor yang paling utama pada bench/fasilitas duduk adalah faktor fungsi yaitu kenyamanan dan safety bagi responden dapat terpenuhi secara maksimal.

\subsubsection{Papan informasi}

Menurut Mujimin [3], papan informasi digunakan untuk menyampaikan informasi kepada masyarakat. Baik itu informasi dari pemerintah atau badan terkait, hingga promosi iklan produk dan jasa. Dalam penggunaannya di halte kota Surabaya, papan informasi yang ada hanya menampilkan/menyampaikan informasi dari fasilitas Suroboyo Bis. Akan tetapi dalam perkembangan nantinya setiap information board akan memiliki bermacam - macam info terkait dengan kota Surabaya seperti layanan masyarakat, info pariwisata dan lain - lain. Pada umumnya penempatan papan informasi diantara 48-67 inchi dari atas tanah merupakan titik penglihatan paling nyaman baik bagi orang biasa maupun berkursi roda [4][5].

Akan tetapi dalam beberapa kasus yang terjadi, salah satu fasilitas halte yang sering menjadi tindak vandalisme adalah information board. Maka dari itu dalam perancangan kali ini, peneliti akan menggunakan material yang cukup untuk menahan aksi vandalisme. Setelah dilakukan perbandingan material, maka penulis akan menggunakan material akrilik sebagai material utama dalam pembuatan information board. Material ini memiliki harga lebih rendah daripada kaca, akan tetapi lebih kuat dan lentur. Sehingga dapat meminimalisir tindak vandalisme. 


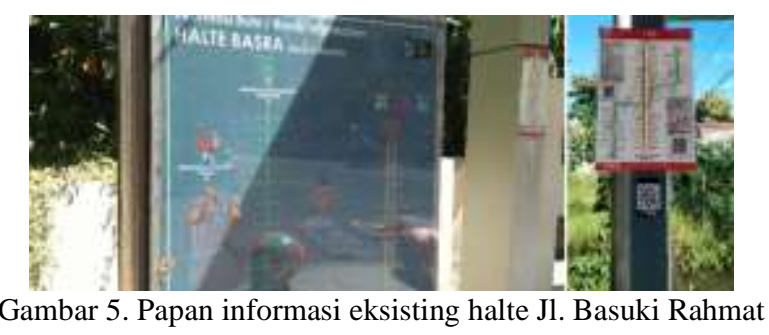

Masalah atau kekurangan terkait papan informasi halte terutama yang ditemukan penulis pada observasi lapangan antara lain adalah : 1) Letak dari Information Board yang tidak sesuai. Letak yang dimaksud adalah seperti tinggi information board yang tidak sesuai dengan aturan ergonomi tentang jarak dan sudut pandangan manusia. 2) Ukuran Information Board yang kecil. Salah satu halte yang memiliki information board kecil adalah halte di bundaran ITS. Hal ini cukup mengganggu terutama para pengguna yang memiliki masalah penglihatan. 3) Informasi rute yang tidak kelihatan. Pada pengamatan penulis, hampir $70 \%$ halte Suroboyo Bus memiliki information board tentang rute yang ukuran hurufnya kecil dan memiliki background hitam yang membuat masyarakat tidak dapat jelas melihat informasi rute.

Berdasarkan dari beberapa permasalahan tersebut, penulis akan mempertimbangkan untuk mencari solusi untuk permasalahan information board pada halte melalui : 1) Membuat information board dengan desain estetika yang menarik dan informatif, 2) Membuat information board yang mengikuti aturan peletakan sesuai aturan ergonomi yang berlaku

\section{a. Ergonomi}

Menurut antropometri manusia secara ergonomis, untuk information board, desain halte ini akan menggunakan acuan ergonomi yaitu sebagai berikut.

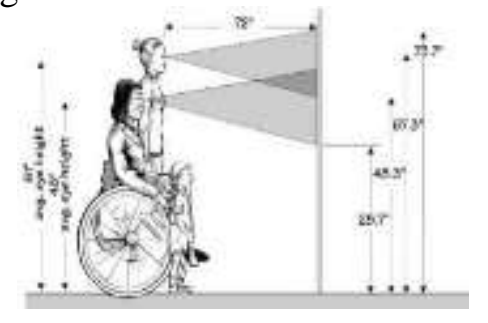

Gambar 6. Ergonomi letak dan ukuran

Papan informasi digunakan untuk menunjukkan rute, jadwal, dan sistem informasi. Papan informasi dapat dipasang pada sebuah tiang atau menjadi satu bagian dengan shelter. Papan informasi akan menjadi sangat krusial pada tempat tunggu kendaraan umum, terutama pada pemberhentian dengan aktivitas lokasi yang tinggi dan yang menjadi titik transfer antar rute [6].

Papan informasi dapat dipasang tinggi mulai dari 27 inci hingga 80 inci dari atas tanah. Gambar menunjukan contoh pemasangan papan informasi yang direkomendasikan, dimana pada umumnya penempatan papan informasi diantara 48-67 inchi dari atas tanah merupakan titik penglihatan paling nyaman baik bagi orang biasa maupun berkursi roda.
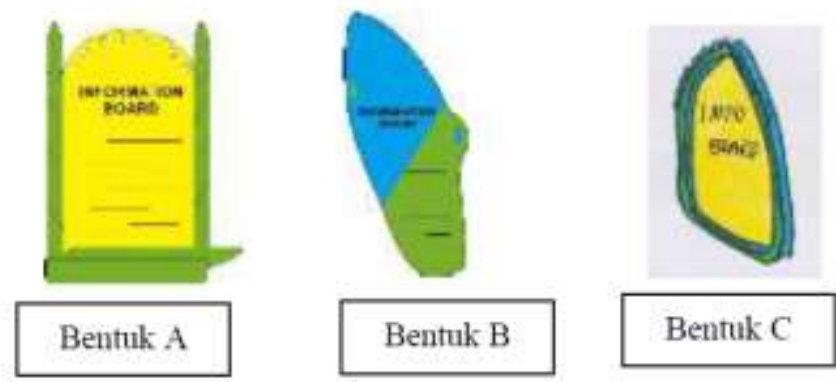

Gambar 7. Bentuk Alternatif Information Board 
Tabel 2. Perbandingan Alternatif Bentuk Information Board

\begin{tabular}{lccccc}
\hline & Visibilitas & Estetika & Kemudahan Produksi & Cost & Total \\
\hline Bentuk A & 5 & 4 & 4 & 4 & 17 \\
\hline Bentuk B & 4 & 2 & 7 & 5 & 18 \\
\hline Bentuk C & 6 & 4 & 6 & 5 & 21 \\
\hline
\end{tabular}

Berdasarkan hasil tabel perbandingan, maka bentuk yang sesuai dan dapat digunakan adalah bentuk C. Hal ini dikarenakan bentuk $\mathrm{C}$ memiiki visibilitas dan kemudahan dalam produksinya. Selain itu memiliki estetika menyerupai rahang seekor ikan hiu yang dimana ikan hiu juga merupakan salah satu ikon khas kota Surabaya.

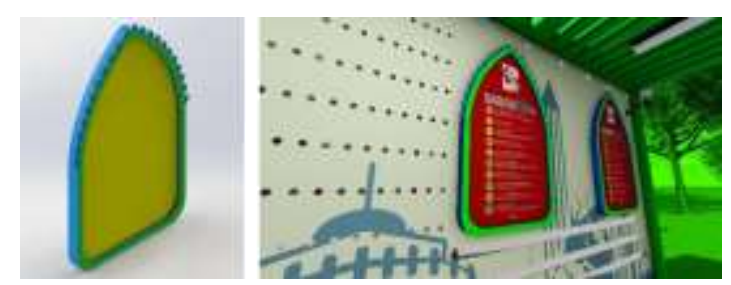

Gambar 8. Bentuk Final Papan Informasi

\subsubsection{Keamanan Halte}

Keamanan merupakan standar minimal yang harus dipenuhi agar responden terhindar dari gangguan perbuatan melawan hukum dan atau rasa takut. Pada halte di Kota Surabaya, faktor keamanan menjadi permasalahan karena adanya tindakan pencurian , premanisme dan lain - lain. Namun beberapa halte Bis Suroboyo masih belum dilengkapi dengan sistem CCTV. Dan meski di beberapa halte lain telah dipasang CCTV, jenis CCTV yang digunakan belum dapat mengatasi keamanan suatu halte akibat jenis CCTV yang memiliki titik buta (area tidak terlihat CCTV). Oleh karenanya penulis akan merancang CCTV yang memiliki sudut putar 360 derajat, sehingga dapat merekam seluruh aktivitas didalam halte.Peletakan CCTV nantinya pada area yang tinggi dan tidak mudah dijangkau orang terutama para pelaku kriminalitas (Pencuri Kelengkapan Halte).

\subsubsection{Kesetaraan Pengguna}

Kesetaraan merupakan standar minimal yang harus dipenuhi untuk memberikan perlakuan khusus berupa aksesibilitas, prioritas pelayanan, dan fasilitas pelayanan bagi pengguna halte penyandang cacat, lansia, anakanak, dan wanita hamil [7]. Fasilitas kesetaraan ini meliputi : Kursi prioritas; Ruang khusus untuk kursi roda; dan Guiding Block

Akan tetapi berdasarkan pengamatan penulis di beberapa titik halte, tidak ada satupun halte di Kota Surabaya yang memiliki fasilitas pendukung untuk menjangkau kesetaraan. Sehingga penulis menjadikan ini sebagai salah satu fokus paling penting untuk desain halte yang akan dibuat, agar semua pengguna tidak ada kesenjangan terutama para masyarakat yang disabilitas. Sehingga halte nantinya akan memiliki fitur keunggulan yakni dari faktor kesetaraan.

Fitur yang akan diterapkan adalah Pemberian Ruang Khusus Pengguna kursi roda dan kursi prioritas bagi wanita hamil dan lansia, serta peningkatan kualitas dari guiding block seperti pewarnaan ulang agar masyarakat tahu dan sadar apabila mereka berdiri di area bagi tuna netra. Sehingga pengguna yang tuna netra tidak terganggu di saat berjalan baik mau menggunakan bus atau hanya sekedar melewati halte. 


\subsubsection{Layout Halte}

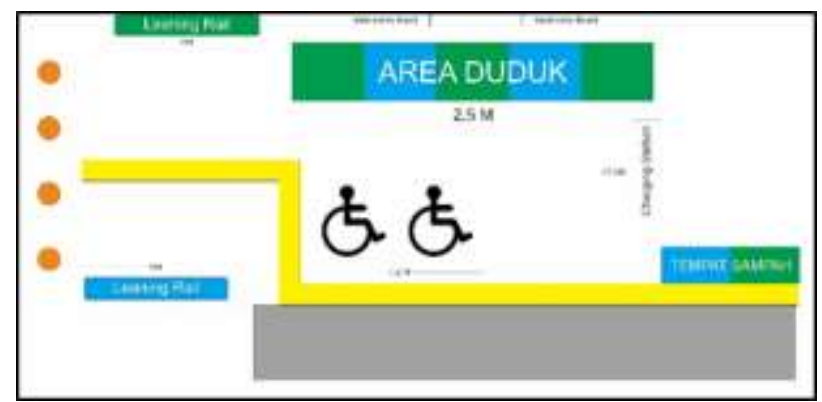

Gambar 9. Layout Halte A

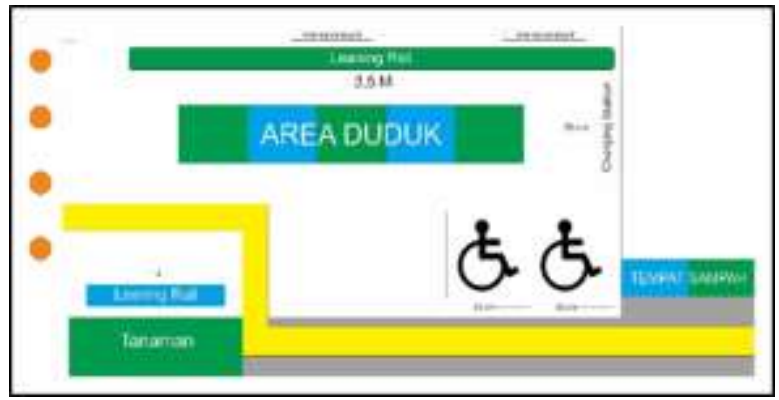

Gambar 10. Layout Halte B

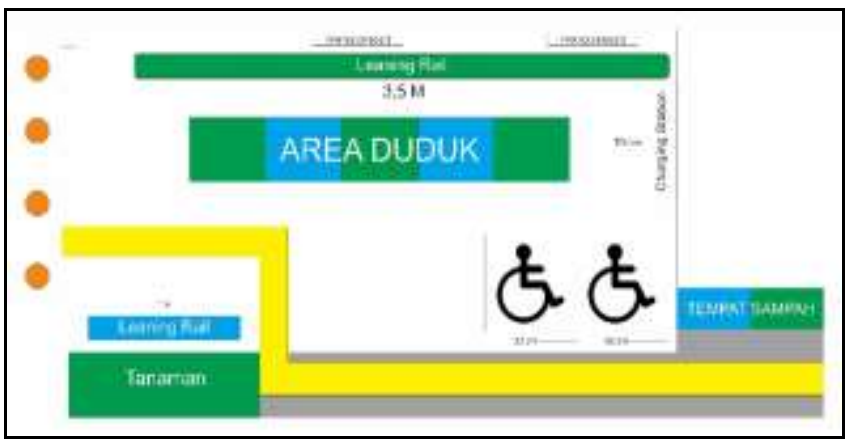

Gambar 11. Layout Halte C

Tabel 3. Perbandingan Alternatif Denah

\begin{tabular}{cccccc}
\hline & Kapasitas & Fasilitas kesetaraan & Safety & Kemudahan sirkulasi & Total \\
\hline Layout A & 6 & 5 & 7 & 8 & 26 \\
\hline Layout B & 5 & 5 & 6 & 5 & 21 \\
\hline Layout C & 6 & 5 & 5 & 7 & 22 \\
\hline
\end{tabular}

Menurut hasil analisa yang didapatkan, maka layout halte yang sesuai dan nyaman bagi masyarakat adalah layout $\mathrm{A}$, hal ini karena layout A dapat menampung kapasitas pengguna lebih banyak, baik pengguna normal ataupun pengguna disabilitas. Selain itu memiliki tingkat safety dan sirkulasi ruangan yang baik agar pengguna tidak berdesakan saat menunggu bus ataupun saat keluar dari bus sesuai dengan sirkulasi yang umum terjadi di dalam halte/shelter.

\subsubsection{Material Halte}

1) Rangka Halte

Rangka halte merupakan unsur paling penting dalam halte. Berdasarkan Tjahyadi [8], rangka atau struktur halte haruslah memiliki kriteria sebagai berikut: 1) Material harus anti karat dan korosi, tahan akan cuaca dan suhu, 2) Material dianjurkan bukan menggunakan bahan yang dapat dirusak hama seperti rayap, 3) Apabila memungkinkan, penggunaan finisihing powder coat juga dapat diaplikasikan dalam pembuatan rangka halte. 
Berdasarkan hasil tersebut maka material yang akan digunakan adalah Baja Galvanis / Galvanized Steel. Yang menjadi keunggulan dari material ini adalah kemudahan dalam segi produksi, ketersediaan baang serta memiliki harga yang lebih kompetitif. Material ini akan dilapisi dengan powder coat agar memiliki ketahanan lebih lama lagi dari cuaca panas atau hujan.

\section{2) Atap Halte}

Atap juga merupakan bagian penting dari sebuah halte karena penempatan halte ada di ruang luar / outdoor. Menurut Guidelines for The Design and Location for Bus Stops [9] yang perlu diperhatikan pada atap halte, yakni atap harus dapat menahan panas dan sinar matahari secara langsung, sehingga pengguna merasa nyaman saat menunggu didalam halte. Lalu atap juga harus tahan akan kondisi segala cuaca agar pengguna tidak khawatir dalam menggunakan halte pada saat cuaca apapun.

Berdasarkan analisa material atap maka material yang digunakan adalah material Polycarbonate. Alasannya adalah bahan material ini mudah di aplikasikan pada halte. Selain itu keunggulan lain adalah tahan akan segala kondisi cuaca dengan harga yang kompetitif. Banyak halte di Surabaya menggunakan material Polycarbonate.

\subsubsection{Bentuk Stasiun Isi Daya (Charging Station)}

Stasiun isi daya yang diperlukan adalah port yang tidak menggunakan daya besar di dalam halte. Yang kedua adalah, port harus dapat memfasilitasi minimal 6 pengguna dan maksimal 10 pengguna. Maka dari itu, penulis menggunakan tipe Port MicroPack USB Charger yang merupakan USB Charger dengan daya listrik dibutuhkan rendah yakni 21 watt namun daya yang dikeluarkan setara dengan kebutuhan pengisian daya gadget pada umumnya yakni 60 Watt dengan slot port 6 lubang.

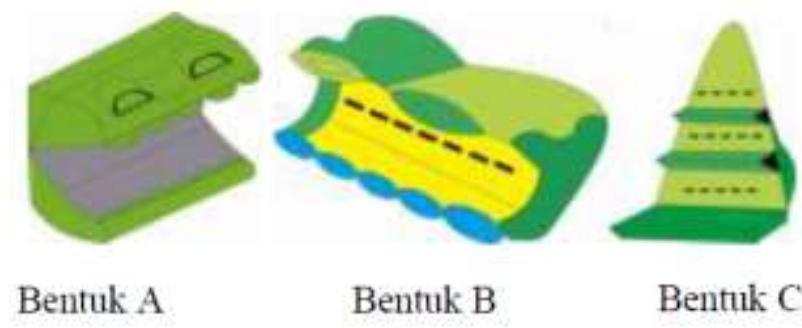

Gambar 12. Bentuk alternatif casing charging station

Tabel 4. Perbandingan Bentuk Casing Charging Station

\begin{tabular}{cccccc}
\hline & Estetika & Safety & Kemudahana produksi & Cost & Total \\
\hline Bentuk A & 7 & 8 & 7 & 8 & 30 \\
\hline Bentuk B & 7 & 6 & 6 & 8 & 27 \\
\hline Bentuk C & 5 & 6 & 8 & 6 & 25 \\
\hline
\end{tabular}

Melihat dari tabel perbandingan, maka bentuk yang sesuai dan dapat digunakan dalam halte adalah bentuk A. Hal ini dikarenakan bentuk A memiliki durability tinggi. Selain itu memiliki estetika menyerupai kepala buaya yang dimana buaya adalah salah satu ikon khas kota Surabaya. Dengan ukuran 40 x $20 \mathrm{~cm}$, proses produksi dari material fiberglass yang mudah dibentuk dan kuat serta biaya murah, sehingga cocok untuk diterapkan di dalam halte yang akan dirancang.

\subsubsection{Bentuk Halte berdasarkan Tema Ikon Surabaya}

1) Bentuk

Halte Bus adalah suatu tempat yang didesain khusus bagi calon penumpang untuk menunggu bus yang akan mereka gunakan. Bentuk halte pun sangat banyak namun cenderung monoton dengan desain bentuk dasar kotak. Sebenarnya bentuk halte di seluruh dunia memang tidak ada standar, sangat tergantung pada kebutuhan spesifik lokalnya.

Seiring dengan majunya perkembangan jaman, gaya desain juga berdampak pada bentuk dan desain dari halte bus di berbagai penjuru dunia, berbagai ide dituangkan untuk mendapatkan desain halte yang semenarik dan 
senyaman mungkin, agar memberikan pelayanan yang terbaik bagi pengguna halte selama menunggu bus yang akan mereka gunakan.

Untuk mengetahui gaya / bentuk desain yang diminati oleh masyarakat Kota Surabaya dalam perancangan Halte bis Suroboyo, maka penulis melakukan observasi kuisioner. Hasil dari wawancara dan kuisioner terhadap 50 responden adalah sebagai berikut:

Hasil pendapat pertama sebanyak 32 responden adalah halte tema desain ikonik. Bahwa 32 responden menyatakan mereka menginginkan bentuk dari sebuah halte yang dapat mencerminkan tentang ke khas-an kota Surabaya ditinjau dari bentuk ikon kota seperti Sura dan Baya.

Hasil pendapat kedua sebanyak 18 responden adalah halte tema desain tropical. Bahwa 18 responden menyatakan mereka memiliki pemikiran bahwa Kota Surabaya sedang mengembangkan dan dikenal sebagai kota Hijau / Green City.

\section{2) Warna}

Warna merupakan salah satu aspek yang cukup penting dalam suatu desain perancangan. Dalam perancangan ini, penulis melakukan pengamatan untuk menentukan warna khas dari kota Surabaya. Hasil pengamatan, kota Surabaya memiliki banyak warna yang saling mengikat satu sama lain, yaitu :

\section{a. Warna Hijau}

Warna hijau sangat kental bagi warga Surabaya sejak lama. Warna hijau muncul dari warna karakter Buaya, musuh Sura pada legenda kisah Sura dan Baya. Sebutan Bajol Ijo / Buaya Hijau merupakan sebutan khusus untuk Klub Sepakbola asal Surabaya yaitu Persebaya.Warna dominan dari Persebaya Surabaya adalah warna hijau yang melambangkan perkembangan dan kehidupan. Hal itu sesuai dengan semangat Persebaya yang aktif dan berkembang untuk mendapatkan prestasi lebih baik. Julukan "The Green Force" yang disematkan pada supporter kesebelasan Persebaya Surabaya, juga memiliki kesan bahwa warna khas kota Surabaya ini adalah warna hijau.

\section{b. Warna Biru}

Warna biru diadaptasi dari ikon kota Surabaya yakni ikon Ikan Hiu / Ikan Sura yang memiliki karakteristik berwarna biru. Warna biru merupakan warna yang paling sering digunakan oleh badan pemerintah termasuk pada logo Pemerintah Kota Surabaya. Selain itu, warna biru juga identik dengan konsep futuristik / smart city, yang merupakan konsep pengembangan untuk tata kota Surabaya di masa mendatang.

\section{c. Warna Kuning}

Warna lain yang cukup melekat pada masyarakat kota Surabaya adalah warna kuning. Alasannya adalah karena warna kuning merupakan warna yang memiliki nada yang seirama / selaras dengan warna hijau atau dapat diartikan memiliki satu kesatuan warna analogus menyerupai skema.

Warna kuning dapat ditemukan dalam beberapa ikon / logo - logo yang ada di kota Surabaya. Antara lain dalam semboyan Green and Clean. Clean dalam Bahasa warna diartikan dengan warna Kuning. Selain semboyan Green and Clean, warna kuning juga dapat ditemukan pada logo

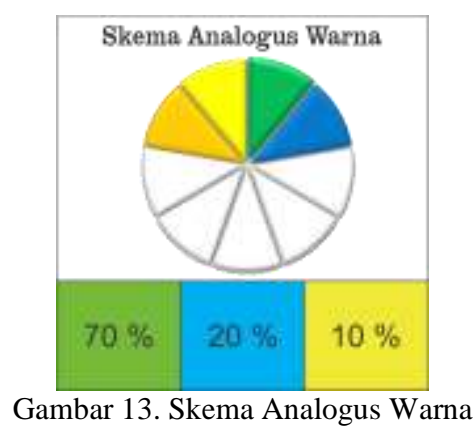

\section{Desain Akhir}

Bentuk dari desain halte ini menyesuaikan dari beberapa hasil pengamatan dan kuisioner kepada responden. Berdasarkan tema desain yang dipilih yakni ikonik bentuk khas Surabaya dengan nuansa tropikal, maka penulis menggabungkan keduanya kedalam pengaplikasian bentuk. 


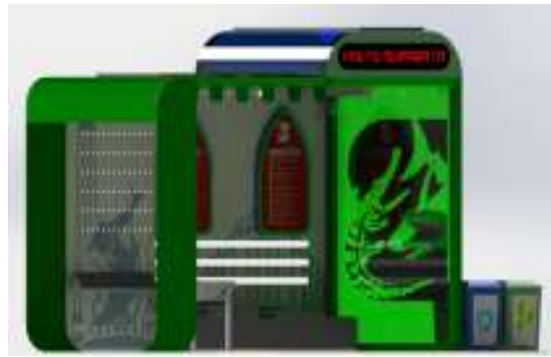

Gambar 14. Bentuk dan Ikonik Halte

Dimensi dari desain halte ini mengikuti aturan dari Dinas Perhubungan dan Pemerintah Kota Surabaya yakni :

Panjang Halte : 4,5 Meter, Lebar Halte : 2 Meter, Tinggi Halte : 3,5 Meter

Pada desain halte ini, ada beberapa keunggulan yang ditawarkan, antara lain adalah:

Memiliki sistem keamanan yang tinggi. Diterapkan pada jenis CCTV yang digunakan. Halte ini nantinya akan menggunakan CCTV dengan sistem sensor gerak, memiliki ruang pantau 360 derajat serta tahan akan tindakan pencurian dan vandalisme. Akan tetapi meskipun anti vandalisme, peletakan daripada CCTV sendiri akan dipasang di area yang tinggi di dalam halte.

Memiliki sarana / fasilitas pendukung kesetaraan bagi penyandang disabilitas, lansia dan wanita hamil. Fasilitas tersebut diterapkan pada warna kursi yakni kursi prioritas adalah berwarna biru sedangkan untuk pengguna normal adalah berwarna hijau. Selain itu warna dari guiding block yang dioptimalkan agar pengguna lain dapat menghargai hak jalan penyandang tuna netra.

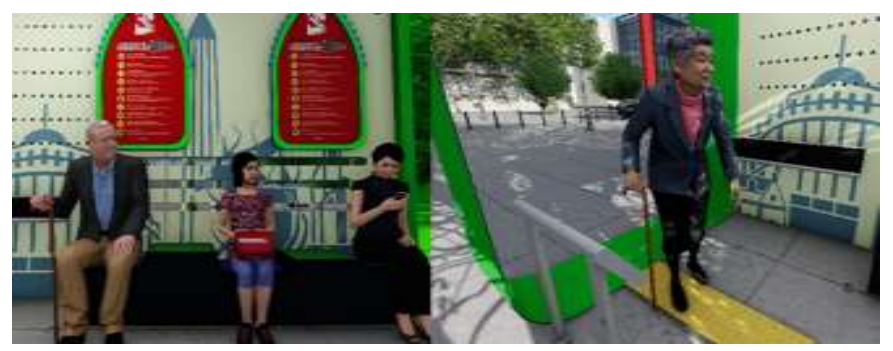

Gambar 15. Fasilitas kesetaraan

1. Memiliki ruang bagi wheelchair hingga 2 pengguna wheelchair. Hal ini dikarenakan pada beberapa halte masih belum menyediakan ruang bagi pengguna wheelchair/kursi roda.

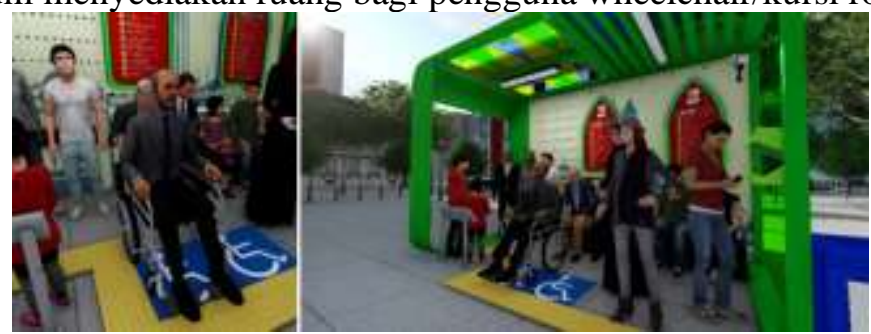

Gambar 16. Fasilitas bagi pengguna kursi roda

2. Merupakan halte pertama di kota Surabaya yang menerapkan charging station bagi mobilitas pengguna yang setiap hari menggunakan fasilitas halte.

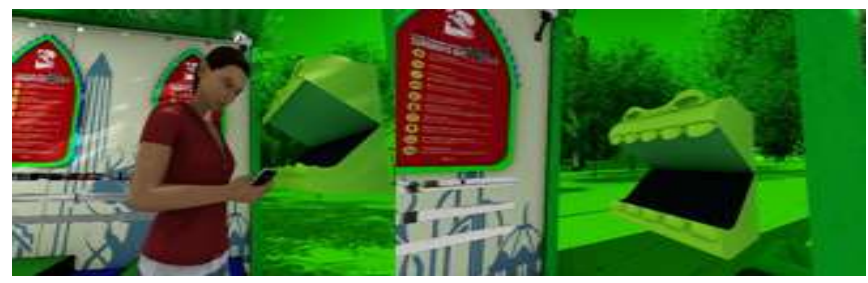

Gambar 17. Penerapan dan penggunaan charging station 


\section{Kesimpulan}

Berdasarkan studi yang telah dilakukan terkait dengan desain shelter angkutan umum studi kasus kota Surabaya, kesimpulan yang dapat diperoleh yaitu:

1. Merancang halte bis yang estetis, nyaman dan aman agar masyarakat mau menggunakan angkutan umum yaitu bis yang telah tersedia.

2. Dengan adanya halte ini, diharapkan minat masyarakat akan angkutan umum bis akan meningkat, sehingga nantinya akan membantu mewujudkan dari Rencana Strategis Pemerintah Kota Surabaya dan Dinas Perhubungan kota Surabaya yaitu adanya moda transportasi yang terintegrasi.

3. Dengan berbagai fitur yang ditawarkan di dalam halte, diharapkan fasilitas dapat menjadi tempat yang menarik untuk digunakan sebagai tempat menunggu, tempat bertukar informasi, dan juga berinteraksi satu sama lain, namun tetap bisa meminimalisir penyalahgunaan fasilitas oleh pihakpihak yang tidak bertanggungjawab. 


\section{Daftar pustaka}

1. Surabaya, P.K., Rencana Strategis Kota Surabaya 2016-2021. 2016, Surabaya: Pemerintah Kota Surabaya.

2. $\quad$ Darat, D.J.P., Pedoman Teknis Perekayasaan Tempat Perhentian Kendaraan Penumpang Umum. 1996, Jakarta: Departemen Perhubungan.

3. Mujimin, W. Penyediaan Fasilitas Publik Yang Manusiawi Bagi Aksesibilitas Difabel. in art \& design. 2007. Yogyakarta: e-proceeding of art \& design.

4. Nurmianto, E., Ergonomi Konsep Dasar dan Aplikasinya, Surabaya. 1991, Surabaya: Prima Printing.

5. Nurmianto, E. Accessible Bus Stop Design Guidance. 2006; Available from: www.tfl.gov.uk,.

6. Authority, W.M.A.T., Guidelines for the Design and Placement of Transit Stops. 2009, Washington: KFH Group.

7. Administration, F.T., Accessibility Handbook For Transit Facilities. 1992, Washington: U.S. Dept. of Transportation.

8. $\quad$ Tjahjadi, D.1.S., Data Arsitek. Vol. 33. 1996, Jakarta: Erlangga.

9. Program, T.C.R., Guidelines for The Design and Location for Bus Stops. 2006, Washington. 